\title{
An Analysis of Within-the-Hour Fading in 100- to 1,000-Mc Transmissions
}

\author{
H. B. Janes
}

\begin{abstract}
An analysis is made of the fading range of 100 - to 1,000-Me transmissions received both within and beyond the radio horizon. The measurements were made during August 1952 over the various Cheyenne Mountain Field Station paths and over the Cedar Rapids, Iowa,Quincy, Ill. path. Fading range is defined as the ratio in decibels of the signal levels exceeded 10 and 90 percent of an hour. For each of the four frequencies studied, the extent to which median fading range and median signal level depend on the angular distance and time of day is shown in the form of graphs and sample recordings. The data show that beyond the region where diffraction is considered to be the dominant mechanism, the signal level distributions closely resemble the Rayleigh distribution in both fading range and general shape. Deviations from the 13.4-db fading range of a Rayleigh distribution are thought to be due to changes in the average signal power during the hour. The method developed by Norton for estimating from the fading range the ratio of the Rayleigh-distributed component of signal to the constant diffracted component is applied to a sample of the data, and the techniques for applying the method to these particular data are discussed.
\end{abstract}

\section{Introduction}

The Bureau's Central Radio Propagation Laboratory has been conducting a long-term program of propagation measurements at its Cheyenne Mountain Field Station in Colorado Springs, Colo. Included in these measurements are frequencies ranging from 100 to $1,000 \mathrm{Mc}$, and propagation over both optical and nonoptical paths. Several transmitting antenna heights are employed so conditions that might be encountered in both ground-to-ground and air-to-ground transmissions can be simulated. Similar long-term measurements have been carried out at a frequency of $418 \mathrm{Mc}$ over the 134-mile path between Cedar Rapids, Iowa, and Quincy, Ill.

The analysis of these data has included a study of the short-term fading, which, in general, characterizes $\mathrm{VHF}$ and $\mathrm{UHF}$ signals transmitted beyond and, to a lesser extent, within the radio horizon. For the purpose of this investigation, short-term fading is defined as those fluctuations in instantaneous signal level that occur within a period of an hour' recording. The two principal factors of interest in studying short-term fading are the extent or range of fading and the rate at which these variations occur. The data recorded during August 1952 have been selected for a rather detailed study of fading range. An attempt has been made to show for these particular frequencies and paths and this time of year, the variation of fading range with time of day and the angular distance, $\theta$. $\theta$ is defined as the angle in the great circle plane between the horizon rays from the transmitting and receiving antennas as determined for a standard atmosphere.

Figure 1 shows examples of within-the-hour fading in $100-\mathrm{Mc}$ transmissions made during alternate hours from two widely separated transmitting antenna elevations and received at three receiving sites. A description of the various transmission paths is given in section 2. These samples serve to illustrate the wide variety of fading characteristics to be observed with various combinations of antenna height and path length. In figure 2, cumulative distributions of instantaneous signal level are plotted, corresponding to two of the hours, 10 to $11 \mathrm{a} . \mathrm{m}$. and 11 to 12 noon, shown in figure 1. All the recorded data were reduced in this way to hourly cumulative distributions of instantaneous signal level, and these distributions were used as the basis of the fading study. Figure 2 also shows graphically the definition of fading range used here; $i$. e., the ratio, in decibels, of the level exceeded 10 percent of the hour to the level exceeded 90 percent of the hour.

\section{General Description of the Propagation- Measurement Facilities}

Figure 3 shows the location of the several transmitting and receiving sites on the Colorado-Kansas path. The profile has been drawn on the basis of a $4 / 3$ earth's radius to allow for standard atmospheric refraction. Transmissions were made at a frequency of $100 \mathrm{Mc}$ from three sites on or near Cheyenne Mountain. The lowest one was a rhombic antenna located about $40 \mathrm{ft}$ above local terrain at the base of Cheyenne Mountain on the Camp Carson military reservation. The middle antenna is a corner reflector located near the summit of Cheyenne Mountain at an elevation of $8,805 \mathrm{ft}$, or approximately $2,500 \mathrm{ft}$ above the surrounding plains. At the summit of Pikes Peak, a yagi antenna was located at an elevation of $14,115 \mathrm{ft}$, or approximately $7,800 \mathrm{ft}$ above the plains. In addition, transmissions were made at 192.8 and $1,046 \mathrm{Mc}$ from the Cheyenne Mountain summit site.

The receiving sites of interest in this study are those at Karval, Colo.; Haswell, Colo.; Garden City, Kans.; and Anthony, Kans. They are located at distances from Cheyenne Mountain of 70, 97, 226, 
and 393 miles, respectively. Half-wave dipoles were used on all frequencies at Karval, Haswell, and Garden City. The heights above local terrain of the 100-, 192.8-, and 1,046-Mc antennas at these three sites were $18.8,17.5$, and $42.7 \mathrm{ft}$, respectively. At Anthony, rhombic antennas located approximately $40 \mathrm{ft}$ above ground were used for the two lower frequencies. A half-wave dipole, mounted in a $10-\mathrm{ft}$ parabolic reflector with its axis $8.5 \mathrm{ft}$ above ground, was used for the 1,046-Mc recordings. A more complete description of the Cheyenne Mountain project facilities is given in [1]. ${ }^{1}$

Figure 4 shows a similar profile for the Cedar Rapids-Quincy path. Three corner reflector receiving antennas were mounted at heights of 30,365 , and $665 \mathrm{ft}$ above ground near Quincy. The transmitting antenna at Cedar Rapids was a pyramidal horn mounted approximately $40 \mathrm{ft}$ above ground.

With the exception of Anthony, received power data at all the receiving sites were recorded by Esterline-Angus recorders having a chart speed of 3 in./hr. At Anthony, chart speeds ranging from $1 \frac{1}{2}$ to $6 \mathrm{in}$./min were used. In addition, at Garden City, Anthony, and Quincy, time-totalizing recorders were employed because the wide and rapid fading encountered at these sites made graphical analysis of Esterline-Angus chart data difficult, if not impossible [2].

\section{The Parameter $\theta$}

In figures 3 and 4 , the angular distance, $\theta$, mentioned previously is shown as the angle formed by the lines drawn between the transmitting and receiving

TABLE 1. $\theta$ Values for transmission paths used in fading-range study

( $\theta$ computed with an earth's radius factor of $4 / 3$ to allow for standard atmospheric refraction)

\begin{tabular}{|c|c|c|c|c|c|}
\hline \multirow{3}{*}{ Receiving site } & \multicolumn{5}{|c|}{ Transmitting sites and frequencies } \\
\hline & \multirow{2}{*}{$\begin{array}{c}\text { Camp } \\
\text { Carson } \\
100 \mathrm{Mc}\end{array}$} & \multicolumn{3}{|c|}{ Cheyenne Mountain } & \multirow{2}{*}{$\begin{array}{c}\text { Pikes } \\
\text { Peak } \\
100 \mathrm{Mc}\end{array}$} \\
\hline & & $100 \mathrm{Me}$ & $192.8 \mathrm{Mc}$ & $1,046 \mathrm{Mc}$ & \\
\hline & \multicolumn{5}{|c|}{ Colorado-Kansas paths } \\
\hline $\begin{array}{l}\text { Karval } \\
\text { Haswell } \\
\text { Garden City.. } \\
\text { Anthony }\end{array}$ & $\begin{array}{c}\text { deg } \\
0.489 \\
.661 \\
2.197 \\
3.895\end{array}$ & $\begin{array}{r}\text { deg } \\
-0.076 \\
.103 \\
1.611 \\
3.353\end{array}$ & $\begin{array}{r}\text { deg } \\
-0.083 \\
.096 \\
1.608 \\
3.346\end{array}$ & $\begin{array}{r}\text { deg } \\
-0.077 \\
.100 \\
1.532 \\
3.428\end{array}$ & $\begin{array}{r}\text { deg } \\
-0.523 \\
-.307 \\
1.183 \\
2.917\end{array}$ \\
\hline \multicolumn{6}{|c|}{ Cedar Rapids-Quincy path } \\
\hline \multicolumn{5}{|c|}{ Receiving antenna height } & $\theta$ \\
\hline \multicolumn{5}{|l|}{$\begin{array}{l}30 \\
365 \\
665\end{array}$} & $\begin{array}{l}\text { deg } \\
1.148 \\
1.002 \\
0.898\end{array}$ \\
\hline
\end{tabular}

${ }_{1}^{1}$ Figures in brackets indicate the literature references at the end of this paper. antennas and their respective horizons in the great circle plane. This angle has been found to be a useful means of describing the extent to which a receiving antenna lies within or beyond the radio horizon of a given transmitting antenna. This has been found preferable to expressing path length in terms of distance in miles, because. $\theta$ takes into account the path length, antenna heights and the slope of the terrain between an antenna and its horizon determined with an effective earth's radius factor of $4 / 3$. The angular distance, $\theta$, is an important parameter in both diffraction and scattering theories [3]. Table 1 lists the values of $\theta$ for each transmission path used in this study.

\section{Median Fading Range and Median Signal Level}

Most of the data presented in this report are the medians of the individual hourly values of fading range and of signal level. Figure 5 shows an example of a distribution from which such a median value of fading range was obtained. The fading ranges for each hour at a given site and frequency were tabulated and a distribution plotted to obtain the median of the hourly fading ranges. This was done for each hour of the day to show the diurnal variation of the median fading range. In addition, the values for all hours of the day were combined (as in the case of fig. 5) to obtain the over-all median values shown in figure 7 .

A similar procedure was used in the signal-level analysis. In this instance, tabulations of individual hourly median levels were made, the hourly median levels being taken from the cumulative distributions of instantaneous signal level, such as those shown in figure 2. From each of these tabulations a distribution of hourly median levels was drawn. Figure 6 is an example of such a distribution. The medians of these hourly medians were used in figure 8 and in the subsequent diurnal-variation curves.

\section{Fading Range Versus $\theta$}

Figure 7 shows the variation of fading range with $\theta$ for the 100-, 192.8-, and 1,046-Mc transmissions over the Colorado-Kansas path and the 418-Mc transmissions over the Cedar Rapids-Quincy link. Each point on the plot represents the median of the individual hourly fading-range values measured during August 1952 on a particular frequency and path. Negative values of $\theta$ indicate a propagation path lying entirely within the radio horizon. The values of $\theta$ shown in this graph range from $-0.52^{\circ}$ for the $100-\mathrm{Mc}$ Pikes Peak-Karval path to $+3.90^{\circ}$ for the Camp Carson-Anthony path. It will be seen that the most rapid increase in fading range with $\theta$ occurs just below the radio horizon in the so-called diffraction region (i. e., for values of $\theta$ from $0^{\circ}$ to about $1^{\circ}$ ). When $\theta$ exceeds a value of about $1^{\circ}$, the receiving antenna is so far below the horizon that 
the predominant part of the signal is received as a result of some mechanism such as atmospheric scattering, in which the received power is small in magnitude and the fading deep and rapid. The dashed line represents the fading range $(13.4 \mathrm{db})$ of a Rayleigh-distributed signal. Such a distribution would result, if the incoming signal consisted of a number of component waves in random relative phase and had a constant average power. For values of $\theta$ greater than about $1^{\circ}$ the fading range appears to level off at very nearly the Rayleigh distribution value of $13.4 \mathrm{db}$. It is interesting to note that for signals received near the radio horizon (i. e., for the Cheyenne Mountain-Karval path, $\theta=-0.08^{\circ}$ and for the Cheyenne Mountain-Haswell path, $\theta$ $=0.1^{\circ}$ ), the fading range appears to be a function of frequency. This is not true of the longer paths, such as Cheyenne Mountain-Garden City $\left(\theta^{\circ}=\right.$ $1.6^{\circ}$ ) and Cheyenne Mountain-Anthony $\left(\theta=3.4^{\circ}\right)$.

For purposes of comparison, figure 8 shows a corresponding plot of the median attenuation relative to free space versus $\theta$ for each of the paths and frequencies represented in figure 7 . As in the case of fading range, the attenuation increases most rapidly in the diffraction region and levels off considerably in the scattering region far beyond the horizon.

\section{Diurnal Variation of Median Fading Range and of Median Signal Level}

Figures 9, 10, and 11 show the variation of median fading range and of median signal level versus time of day for the various paths and frequencies. These curves were obtained from the monthly distributions of fading range and median signal level for each hour of the day; i. e., the lines join points, each of which represents a median of the hourly values recorded during that particular hour.

Figure 9 shows the diurnal variation of signal level and fading range at Karval, Haswell, Garden City, and Anthony for the 100-Mc transmissions from each of the three transmitting elevations used. The value of $\theta$ for each path is indicated on the figures along with the number of hours of recording on which the curves are based. Unfortunately, there were not sufficient hours of Pikes Peak transmissions recorded at Karval or at Garden City to justify a diurnal analysis. There is a very apparent diurnal pattern in both the median signal level and median fading range for the Cheyenne Mountain and Camp Carson transmissions recorded at Karval and Haswell. These paths range in $\theta$ from $-0.076^{\circ}$ to $0.661^{\circ}$, which means that the receiving antennas were located either just within the radio horizon or slightly beyond the horizon in the region where diffraction is considered to be the dominant propagation mechanism.

For smaller values of $\theta$, such as $-0.307^{\circ}$ for the Pikes Peak-Haswell path, although there is still a definite diurnal pattern in the median signal level, the fading range has decreased to a very small value, and there is no apparent variation in it with time of day, at least as far as could be detected by these measurements. Similarly, for larger values of $\theta$, such as the Garden City recordings from Camp Carson and Cheyenne Mountain ( $\theta$ equals $2.20^{\circ}$ and $1.61^{\circ}$, respectively), there is clearly a diurnal variation in median signal level, but the fading range appears to be influenced very little or perhaps not at all by time of day. In the data recorded at Anthony from Pikes Peak, Cheyenne Mountain, and Camp Carson $(\theta$ equals $2.92^{\circ}, 3.35^{\circ}$, and $3.90^{\circ}$, respectively), there is a diurnal pattern in the median signal level and what appears to be a slight variation in fading range. The latter effect may be caused by a partial mixing of the weak afternoon signal with noise at this most distant recording site. This would result in an apparent rise in the 90-percent level and a corresponding decrease in fading range. The mixture of signal and noise was not a problem at the nearer sites.

Figure 10 shows similar diurnal-variation curves for the 100-, 192.8-, and 1,046-Mc transmissions from Cheyenne Mountain received at each of the four receiving sites. It will be seen that not only is the median signal level apparently a function of frequency at Karval and Haswell, as was mentioned previously, but the extent of the diurnal variation of fading range likewise appears to be a function frequency.

Figure 11 shows the diurnal variation information for the 418-Mc transmissions from Cedar Rapids, Iowa, received at three antenna heights at Quincy, Ill. The angle $\theta$ for the three antenna heights ranges from $0.90^{\circ}$ to $1.15^{\circ}$. Here, as in the case of the Garden City data shown in figures 9 and 10, there is no apparent diurnal variation in fading range, although the median signal level shows very wide variation for all three antenna heights.

\section{Average Distribution of Instantaneous Signal Level}

The data thus far have consisted only of median values of fading range. In some practical applications, it might be desirable to know more about the expected cumulative distribution of instantaneous signal levels than merely the fading range as defined here. In order to obtain a representative distribution for a given hour of the day, transmission path, and frequency, each individual hourly distribution was tabulated in terms of received power relative to the median signal level for that hour. Specifically, they were tabulated in terms of the percentage of time that the signal exceeded each of 10 levels spaced at $2-\mathrm{db}$ intervals above and below the median. These percentages were then averaged for each of the 10 levels, and an "average" distribution of instantaneous levels was drawn. For the Cheyenne Mountain-Haswell and Pikes Peak-Haswell paths, where the range of variation was comparatively small, intervals smaller than 2 -db were used. 
In figure 12 average distributions are shown for each of the propagation conditions studied at Haswell (i. e., 3 transmitting antenna heights for $100 \mathrm{Mc}$ and the 3 frequencies transmitted from Cheyenne Mountain). An early morning and an early afternoon hour were chosen because in general the signal level is at a maximum and minimum, respectively, during these periods. These curves are principally intended to illustrate the general character of the distributions of instantaneous signal level for the various paths and frequencies. However, they also serve to point out some of the effects discussed in connection with the diurnal-variation curves and the fading range versus $\theta$ plot. For example, on $100 \mathrm{Mc}$, the slope of the curve, and hence the fading range, increases sharply with increasing $\theta$. There is also a slight increase in slope with increasing frequency, but, as can be seen more clearly in the Haswell curves in figure 10, this effect is noticeable only during the night and early morning hours. Figure 13 shows the corresponding curves for the Garden City site. Here, in contrast to Haswell, a change in $\theta$ or in frequency appears to have little effect on the fading range, and the same is true in general of the Anthony and Quincy distributions shown in figures 14 and 15. On each of the graphs, the dashed line represents the Rayleigh distribution.

It should be pointed out that fading ranges obtained from these curves should probably be termed the "expected" fading ranges, whereas the values plotted in the previous figures were the medians of the individual hourly fading ranges. It has been found, however, that in most cases these expected values obtained from the average distribution curves varied only a small amount from the median fading ranges.

From the standpoint of practical application it might seem desirable to have defined fading range as the ratio of the 1 - to the 99-percent level. However, obtaining fading-range data based on this definition would have involved considerable extrapolation of the hourly distribution curves derived from the time-totalizing recorders. For this reason, it is felt that the 10- and 90-percent levels provide a much more accurate and more easily obtainable measure of fading range. Estimates of the 1- and 99-percent levels could be obtained by extrapolating the average distribution curves, and they would probably be no less accurate than the values obtained by extrapolation of the individual hourly distributions.

If it is assumed that the signal is composed of a steady component superimposed on a Rayleighdistributed signal, the slope of the resulting signallevel distribution plotted on Rayleigh graph paper will be decreased. Norton [3,4] has developed a method for estimating from the slope of the distribution, the ratio of the rms magnitude of the Rayleigh-distributed component to the magnitude of the steady component to give the resulting dis- tribution. This is illustrated in figure 16, which shows a comparison of the distribution for the hour 1 to 2 p. m. over the Cheyenne Mountain-Haswell path with the computed distribution for $K$ equal to $-19 \mathrm{db}$, where $K$ is the ratio in decibels of the rms Rayleigh-distributed signal to the constant component. Such a small value of $K$ would be expected here because Haswell lies only slightly below the horizon of Cheyenne Mountain, and during the afternoon the predominant part of the signal probably arrived by way of diffraction. It should be pointed out that estimating $K$ from the slope of the distribution curve is valid only if the average energy contained in either component does not vary during the hour [4]. Determination of the ratio of constant to Rayleigh-distributed component from the observed fading range is illustrated in figure 42 of NBS Circular 554 [1].

\section{Discussion of the Chart Samples}

Figure 1 and figures 17 through 23 are samples of Esterline-Angus chart records, which were chosen as being typical of the various paths and frequencies included in this study. Figure 1 shows $100-\mathrm{Mc}$ signals received at Karval, Haswell, and Garden City and transmitted alternate hours from Camp Carson and Cheyenne Mountain. Figure 17 shows signals transmitted from Cheyenne Mountain and Pikes Peak and received at Haswell and Garden City. They serve to illustrate the fact that for small values of $\theta$, both the median signal level and the fading range are very critical to changes in $\theta$. However, for larger values of $\theta$, such as those at Garden City, the signal level and, more particularly, the fading range is affected comparatively little by changes in $\theta$.

Figures 18 to 20 show sample recordings at 100 , 192.8, and 1,046 Mc received at Karval, Haswell, and Garden City. From these it is evident that not only is fading range a function of frequency at Karval and Haswell (i. e., near the radio horizon); but, if we define the rate of fading as the number of times the signal level crosses the median level in a given period, it is seen that the rate of fading is also a function of frequency at all three sites. Figures 21 and 22 show similar samples recorded at Anthony on the same frequencies. These were made at much more rapid chart speeds, and it is evident that the dependence of fading rate on frequency holds even for these large values of $\theta$. These samples also show that there can be wide variations in fading rate from day to day. The signals in figure 21 were recorded during the morning hours of August 16 and those in figure 22, during the afternoon of the next day while there were local thunderstorms in the vicinity of Anthony. This variation in fading rate with time of day is also illustrated in figure 23 , which shows sample $418-\mathrm{Mc}$ recordings at Quincy. Although the characteristics of the fading appear to be approximately the same for all three antenna 
heights at Quincy, there is a very marked decrease in fading rate during the early evening hours.

In connection with fading rate, it should be noted that the time constant of the recording circuits used is approximately $1 \mathrm{sec}$., the limiting factor being the time constant of the recording meter itseli.

\section{Conclusions}

When plotted as functions of $\theta$, fading range and signal attenuation relative to free space exhibit some very similar properties. Within the radio horizon, $\theta<0$, the fading range is very small, the median value for all hours of the day being in all cases studied less than $2 \mathrm{db}$. Beyond the radio horizon in the so-called diffraction region, fading range and signal attenuation both increase very rapidly with $\theta$. For values of $\theta$ greater than approximately $1^{\circ}$, the signal attenuation increases much more slowly, and the fading range levels off at very nearly the Rayleigh distribution value of $13.4 \mathrm{db}$.

It was found that there is a definite diurnal variation in fading range measured in the vicinity of the radio horizon. The fading range increases during the evening hours, drops again in the morning, and reaches a minimum during the afternoon at about the same time the signal level is also at a minimum. The amount of nocturnal rise in fading range near the radio horizon appears to be a function of frequency.

The diurnal variation of fading range tends to disappear as the receiving terminal is moved farther below the radio horizon; i. e., for paths having values of $\theta$ equal to, or greater than, about $1^{\circ}$.

It was pointed out previously that, assuming the received signal consists of a constant component plus a Rayleigh-distributed component, it is possible to estimate the ratio $K$ of the magnitudes of the two components from the slope of the distribution curve; i. e., from the fading range. The difficulty in applying this method to an hourly distribution is that what would normally be called the "constant" component often varies considerably during an hour's time. For example, the diurnal variation in fading range near the radio horizon is largely due to relatively slow and deep fades occurring during the night.

If some smaller increment of time, say 5 or 10 min., were employed in this fading analysis, the results could be expected to be substantially different from those reported herein. In fact, the diurnal variation in fading range at Haswell, for example, might be completely inverted if the time interval were sufficiently small. This is because the fading at night is so slow that a time interval that would include numerous fades during the afternoon might include only a small portion of a fade at night. This would suggest the desirability of further fading studies in which a variety of time increments would be employed. In this way an increment could be chosen for a particular group of data, which would permit analysis of the constant and random components. Such a study would necessarily deal with fading rate as well as fading range.

This paper is an expanded and revised version of one entitled "An analysis of short-term fading in 100-1000 Mc propagation measurements beyond the radio horizon," by A. P. Barsis, H. B. Janes, and C. J. Roubique, which was presented at the joint URSI-IRE meeting in Washington, D. C., April 27 to 30,1953 . The author thanks Barsis and Roubique for their valuable assistance in the initial phases of the study, and Georgia J. Haines, R. W. Hubbard, and M. T. Decker for their work in analyzing the data.

\section{References}

[1] A. P. Barsis, J. W. Herbstreit, and K. O. Hornberg, Cheyenne Mountain tropospheric propagation experiments, NBS Circular 554 (Jan. 1955).

[2] R. P. Decker, Notes on the analysis of radio propagation data, Proc. IRE 22, 1382 (Nov. 1951).

[3] K. A. Norton, The role of angular distance in tropospheric radio wave propagation. Unpublished paper presented at the IRE Convention, San Francisco, Calif., Aug. 19 to 21,1953 .

[4] K. A. Norton, Propagation over rough terrain, p. 101, Report of Symposium on Tropospheric Wave Propagation, U. S. Navy Electronies Laboratory, San Diego, Calif. (July 1949). 

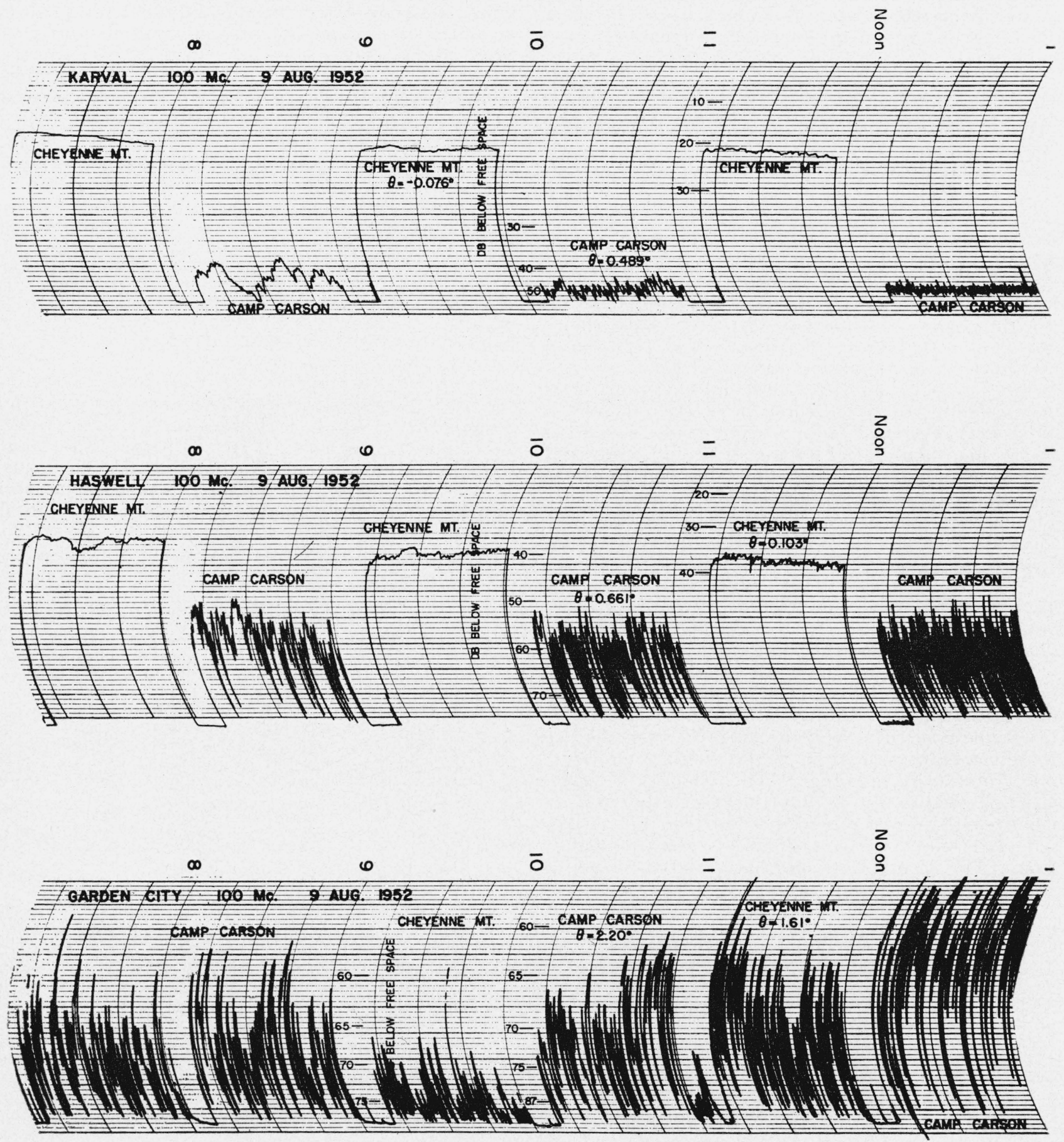

FIGURE 1. Comparison of fading characteristics in relation to angular distance below the radio horizon. 

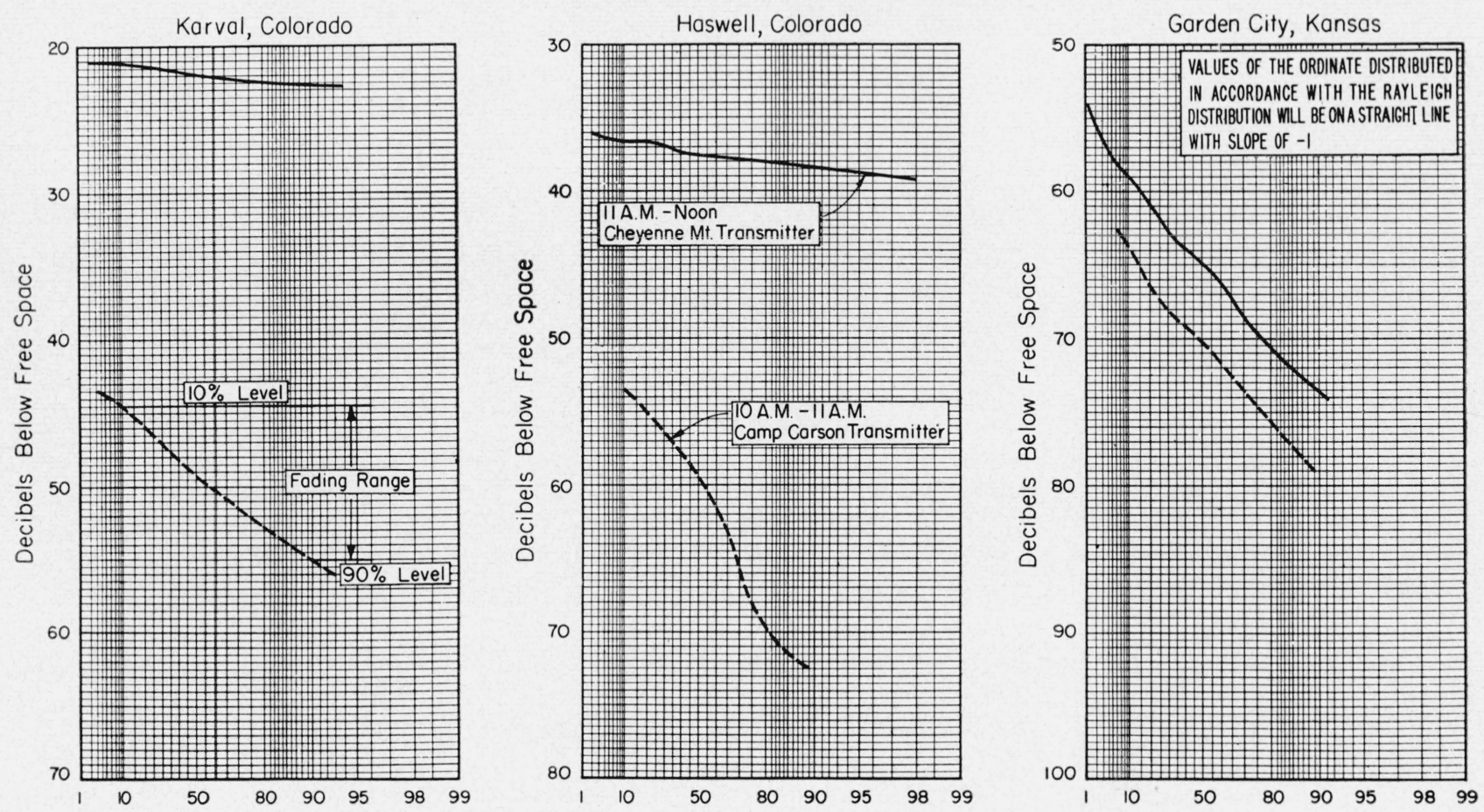

Percentage of Time the Values are Less than the Ordinate

Figure 2. Sample distributions of instantaneous signal levels for two of the hours shown in figure 1, August 9, 1952, 100 Mc

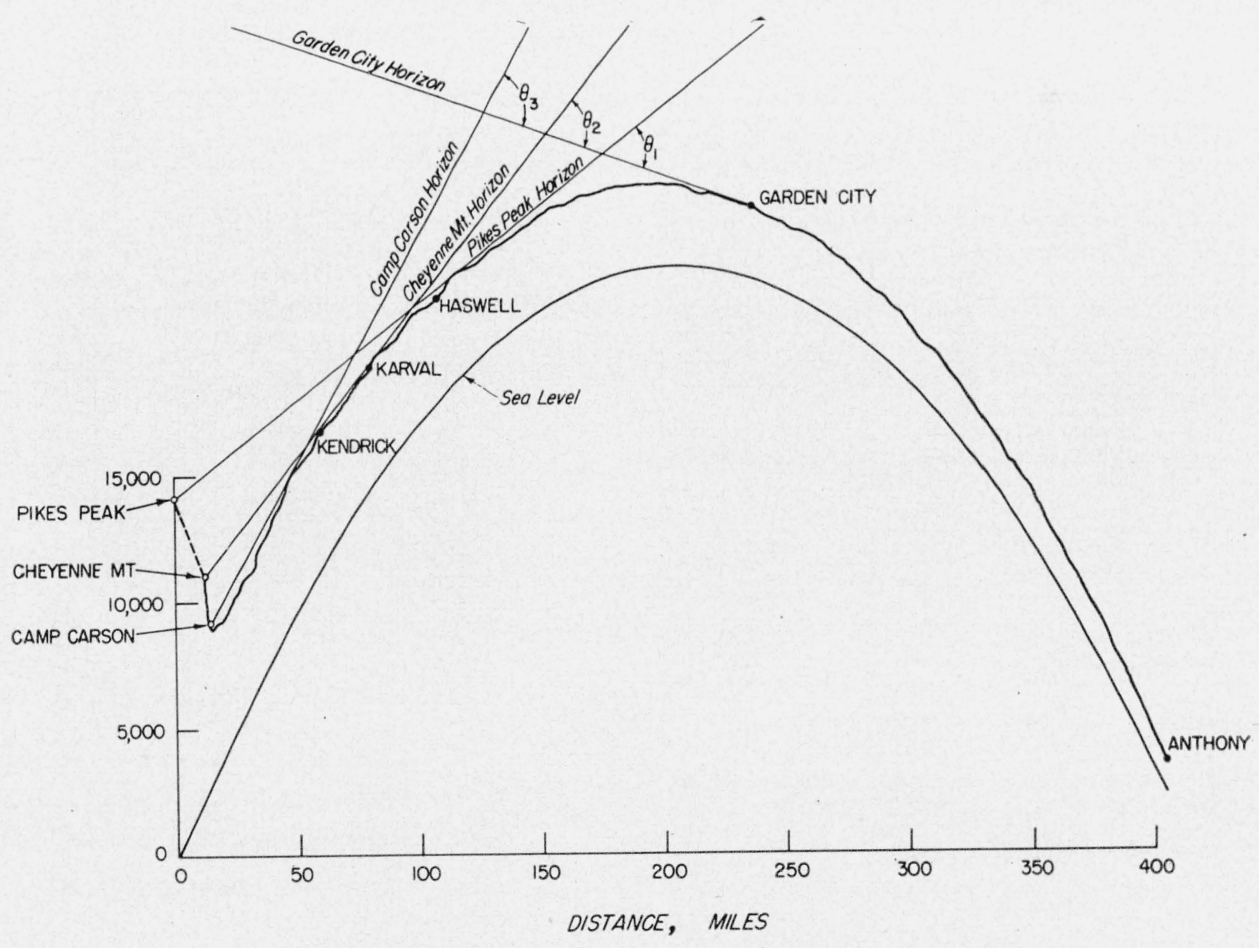

FIgure 3. Terrain profile of Colorado-Kansas paths. 


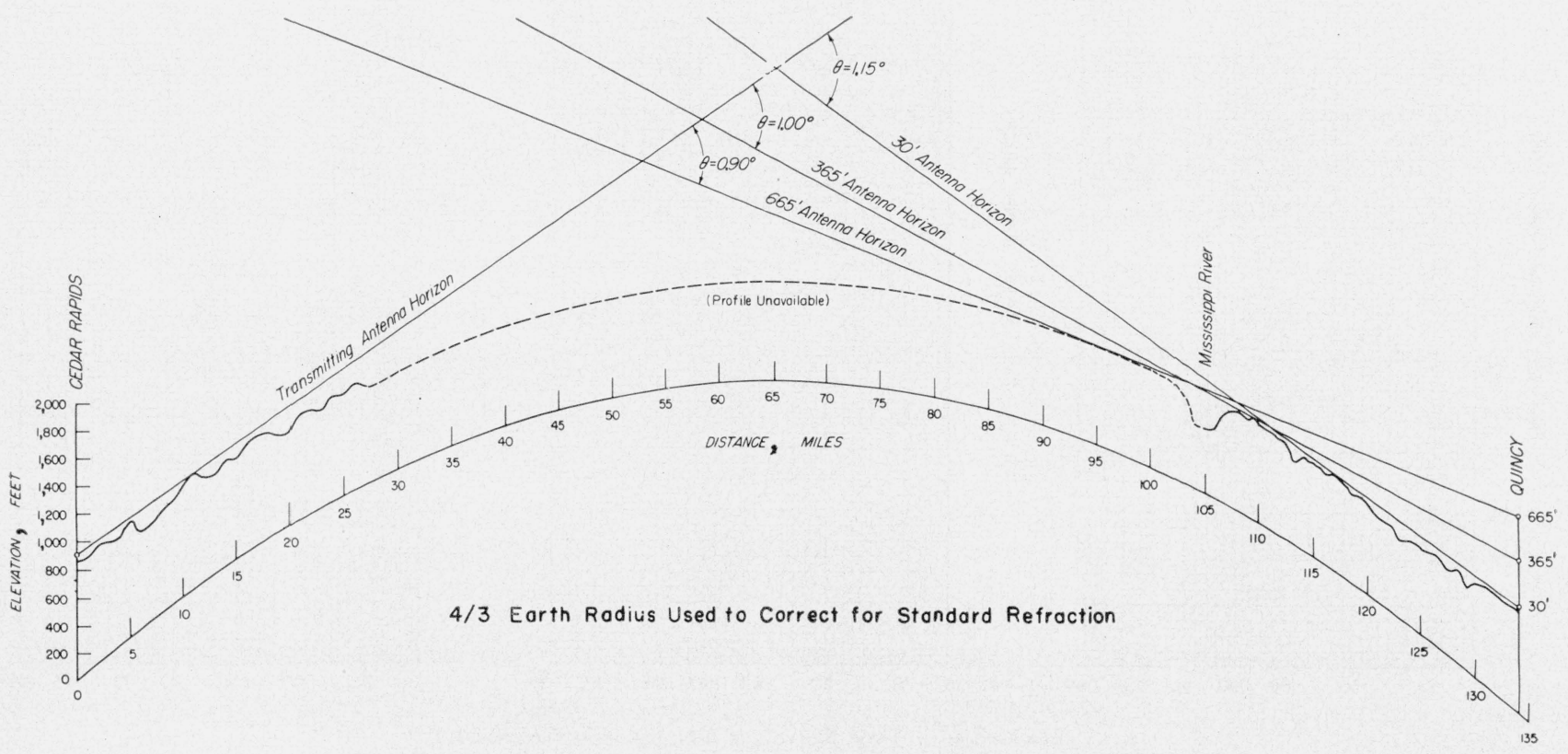

Figure 4. Terrain profile of Cedar Rapids-Ouincy path.

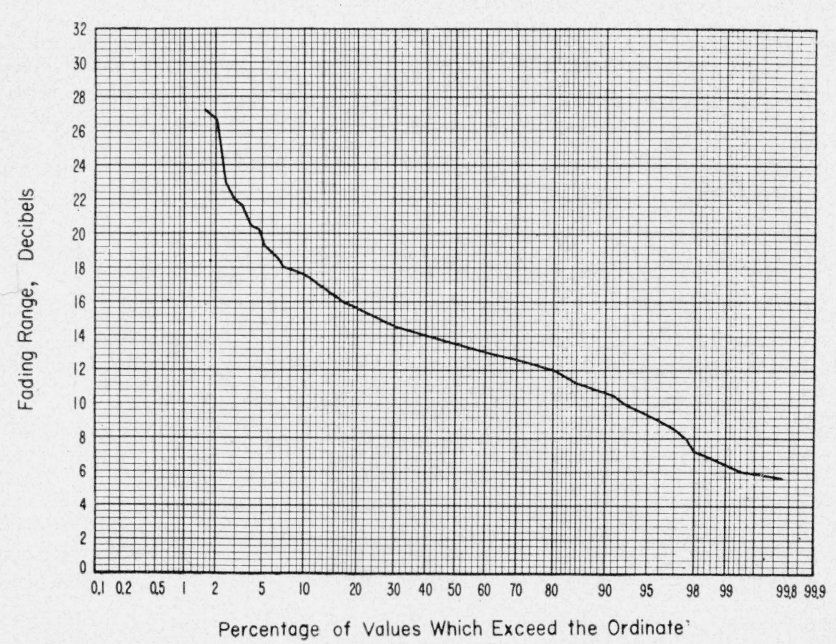

Figure 5. Distribution of fading-range values, Cedar Rapids-Quincy path, August 1952, $418 \mathrm{Mc}$.

Receiving-antenna height, $365 \mathrm{ft}$.

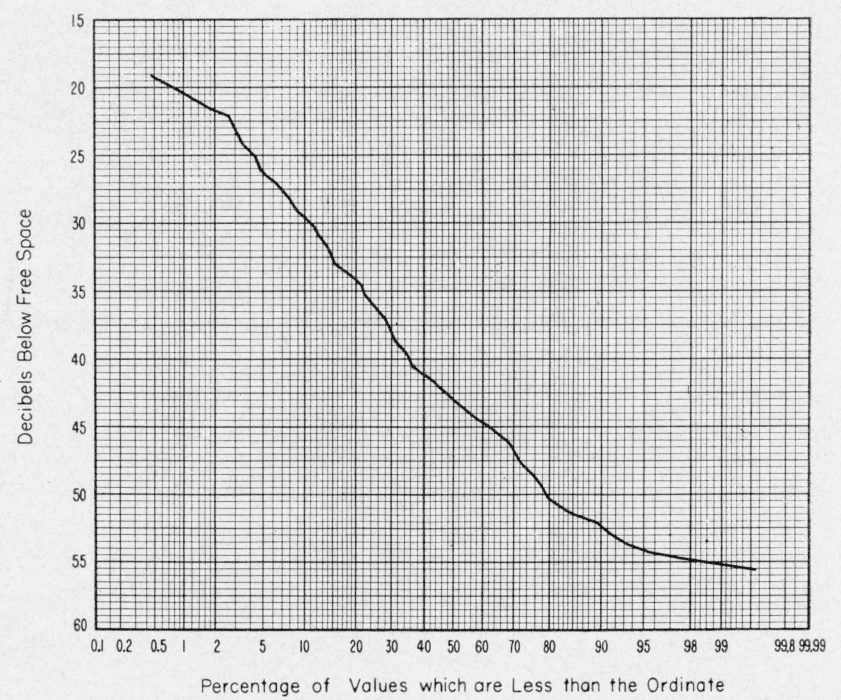

Figure 6. Distribution of hourly median signal levels, Cedar Rapids-Quincy path, August 1952, $418 \mathrm{Mc}$.

Receiving-antenna height, $365 \mathrm{ft}$. 


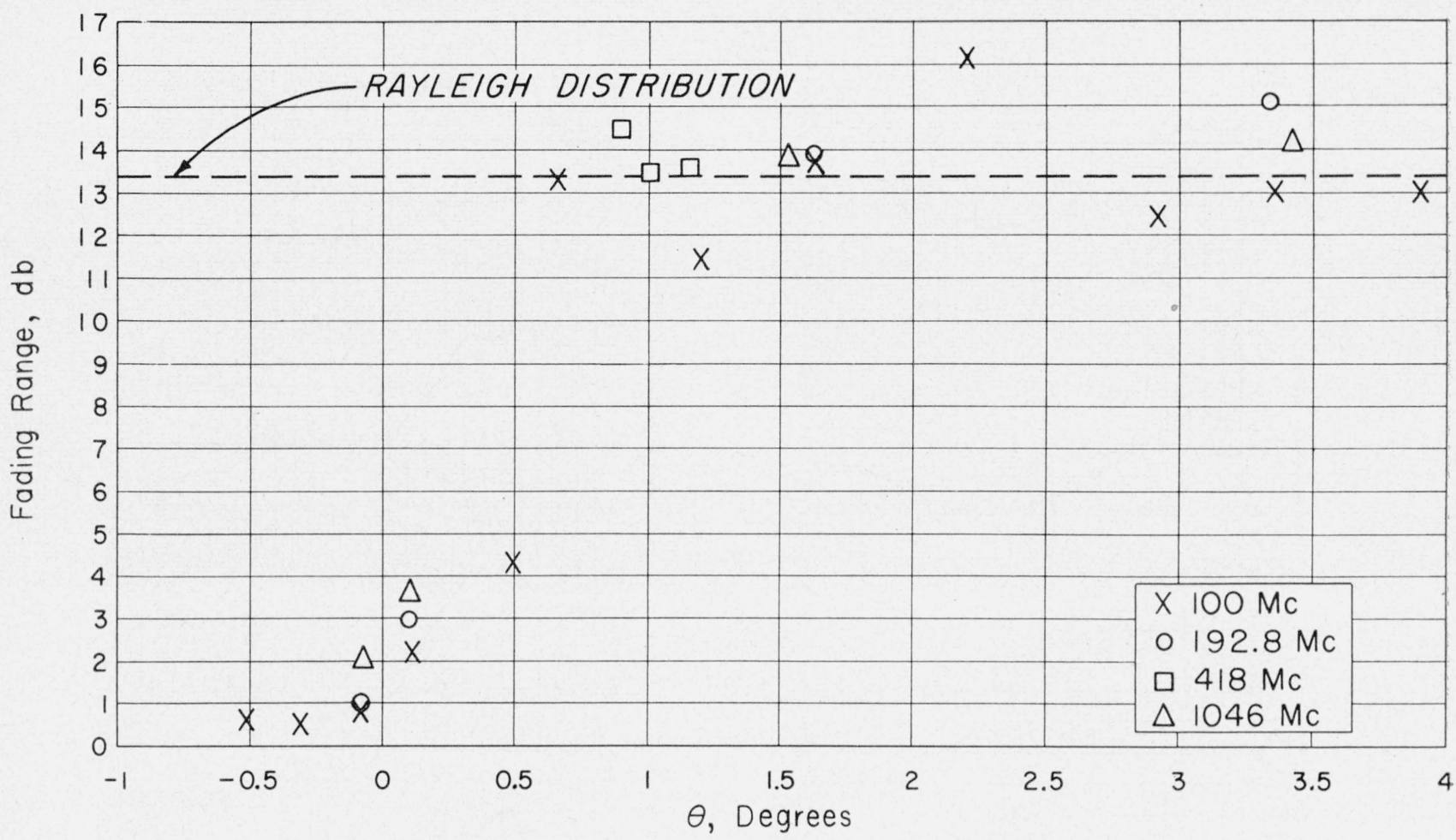

FiguRE 7. Dependence of fading range on the angular distance below the horizon. $\theta$ calculated, assuming standard atmospheric refraction, August 1952 data.

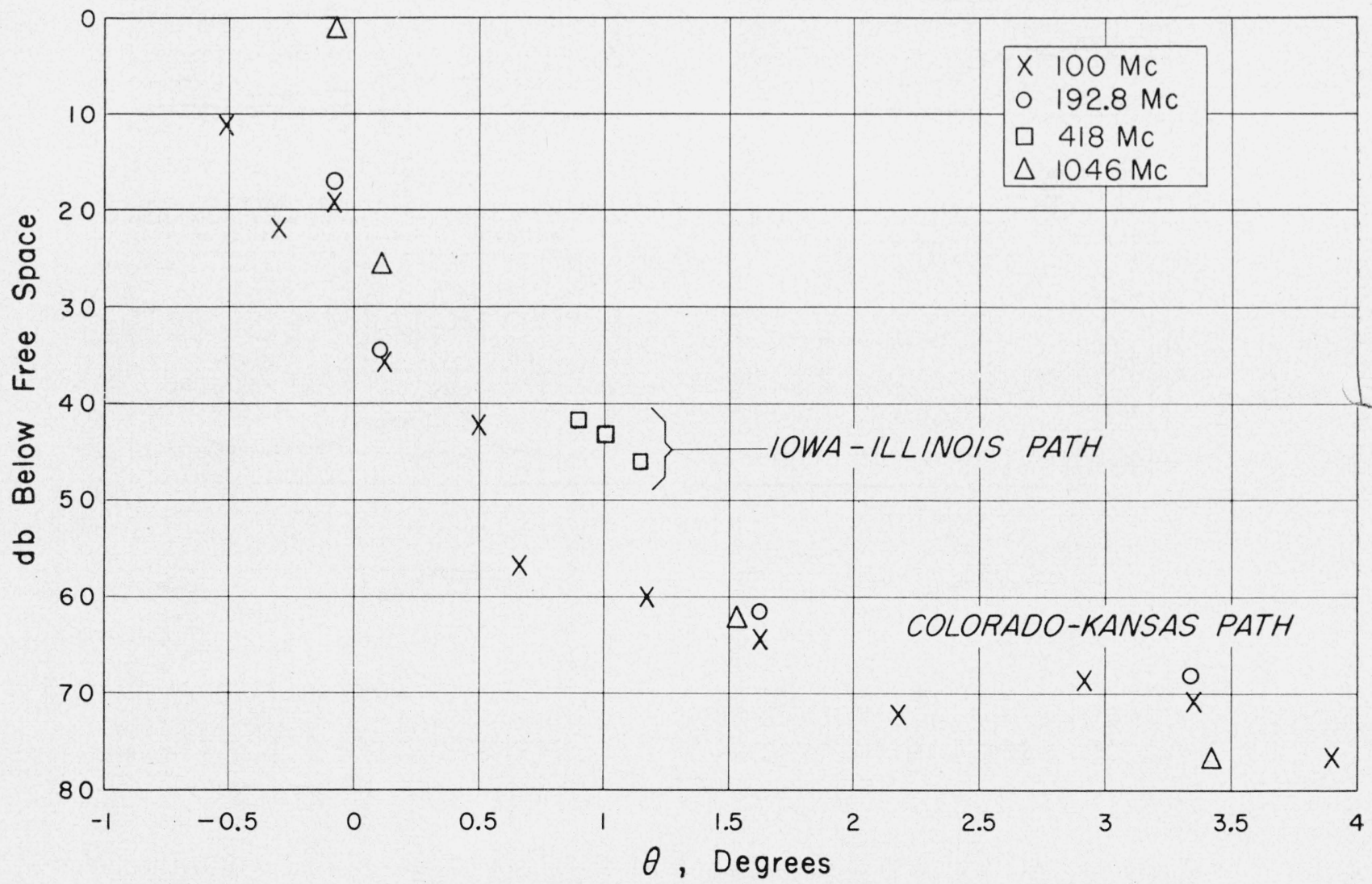

FIGURE 8. Dependence of attenuation relative to free space on the angular distance below the horizon. $\theta$ calculated, assuming standard atmospheric refraction, August 1952 data. 

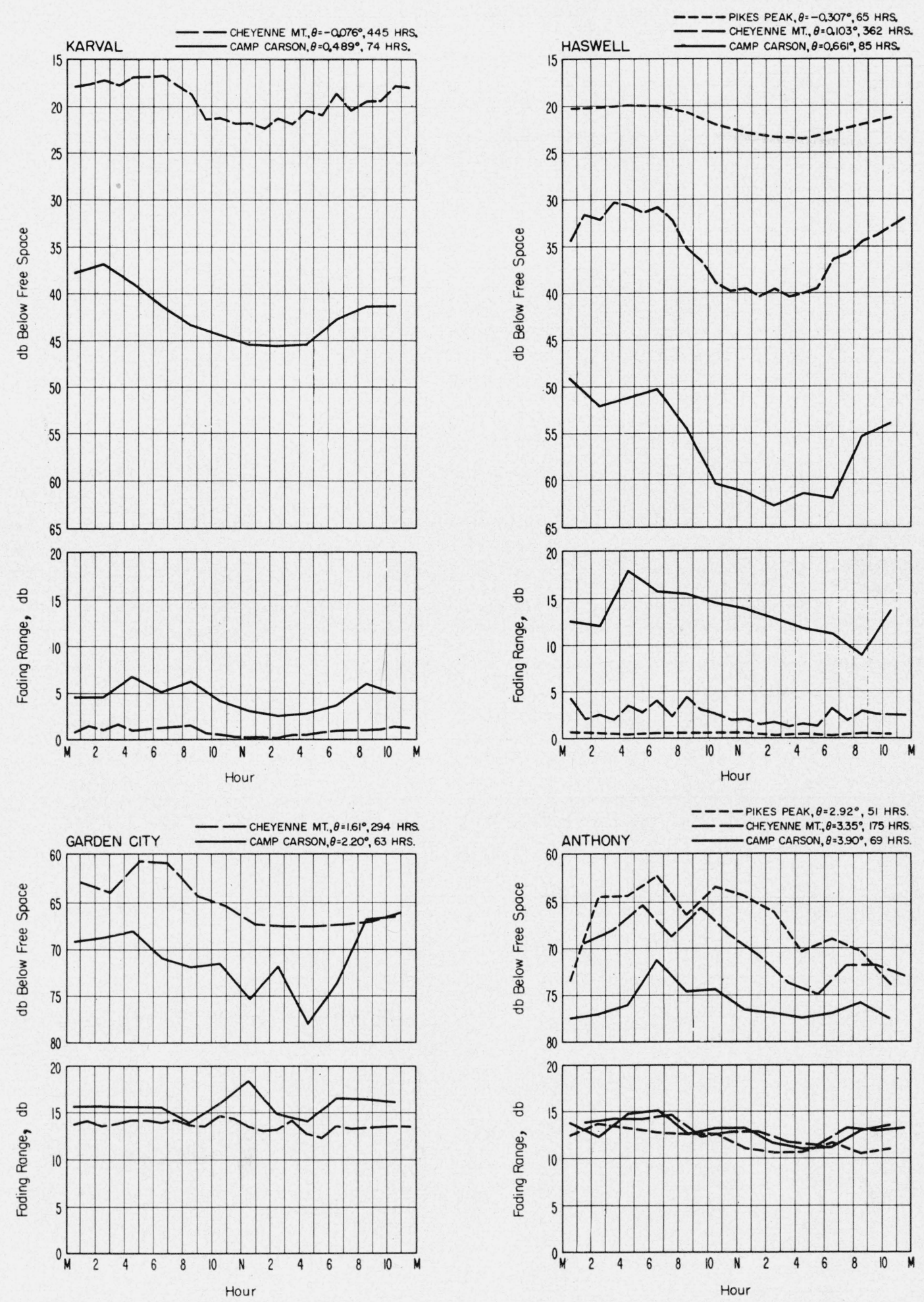

Figure 9. Diurnal variation of median attenuation and of median fading range, August 1952, $100 \mathrm{Mc}$. 

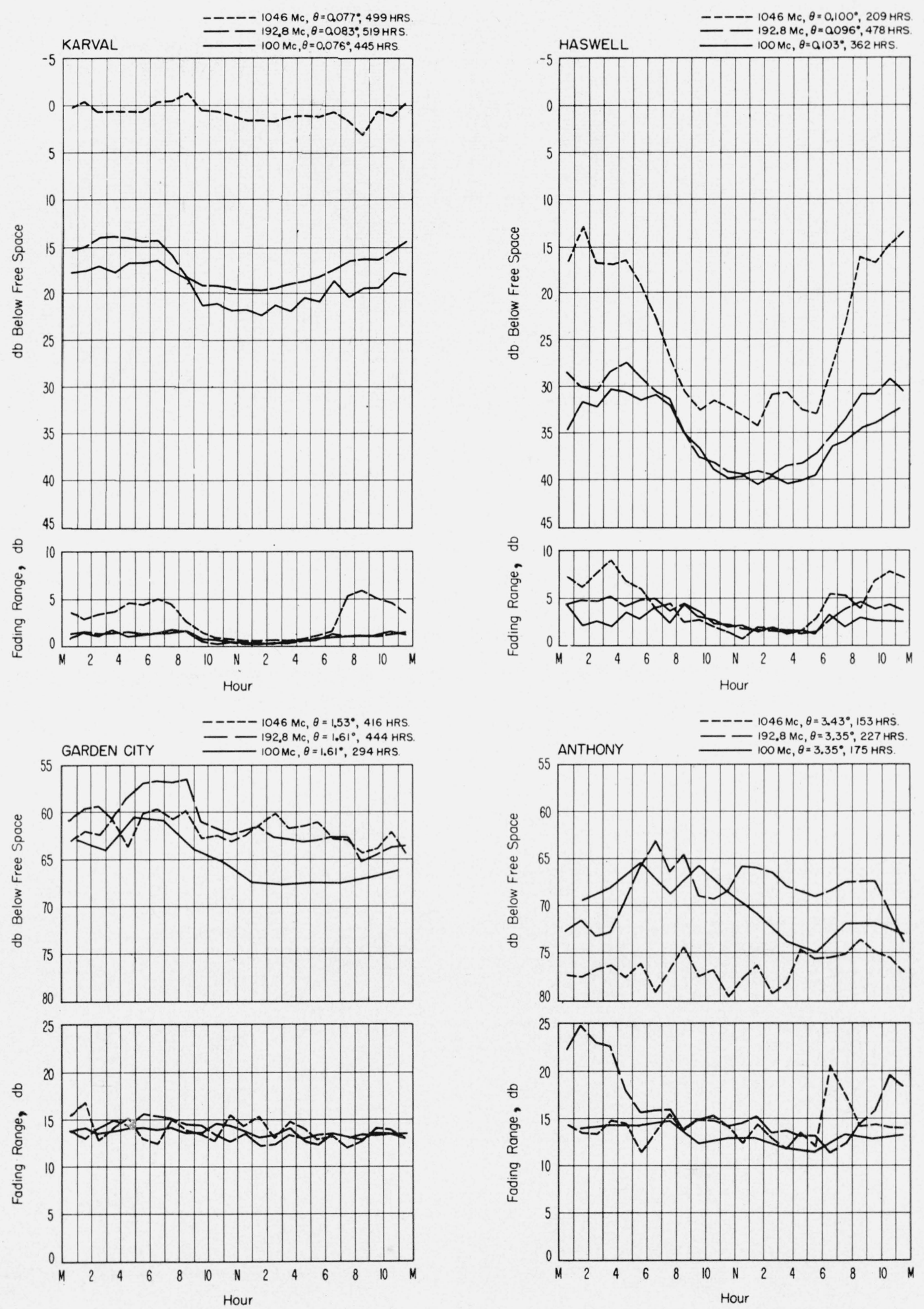

FIGURE 10. Diurnal variation of median attenuation and of median fading range from Cheyenne Mountain, August 1952 

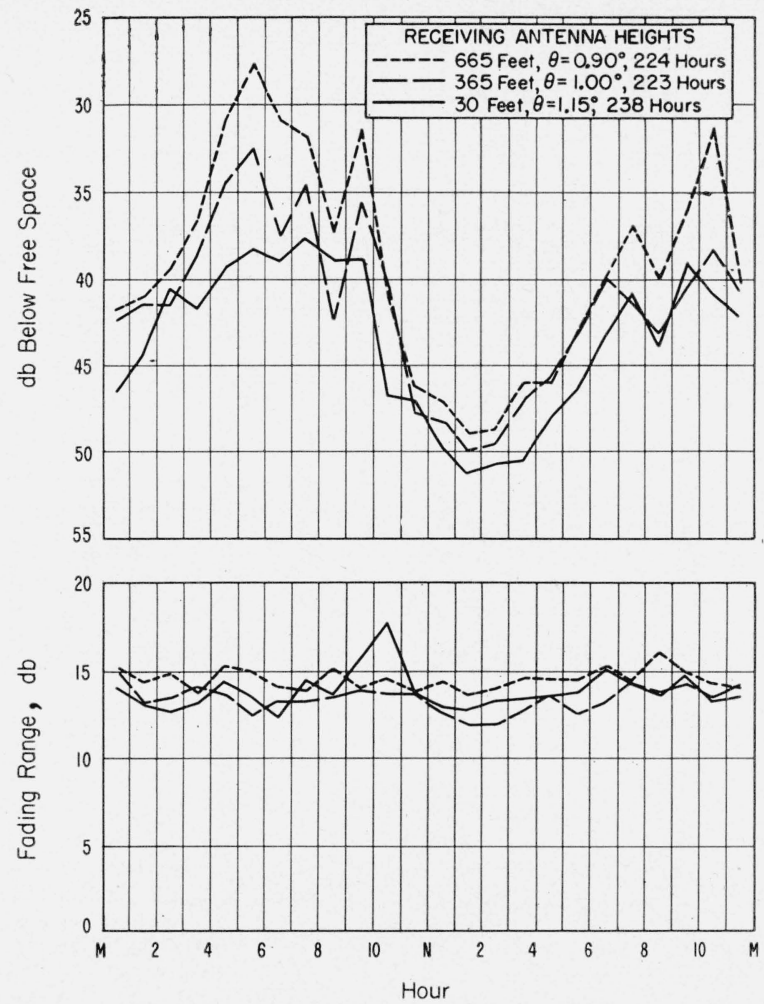

FIGURE 11. Diurnal variation of median attenuation and of median fading range, Cedar Rapids, Iowa to Quincy, Ill., August 1952, 418 Mc.
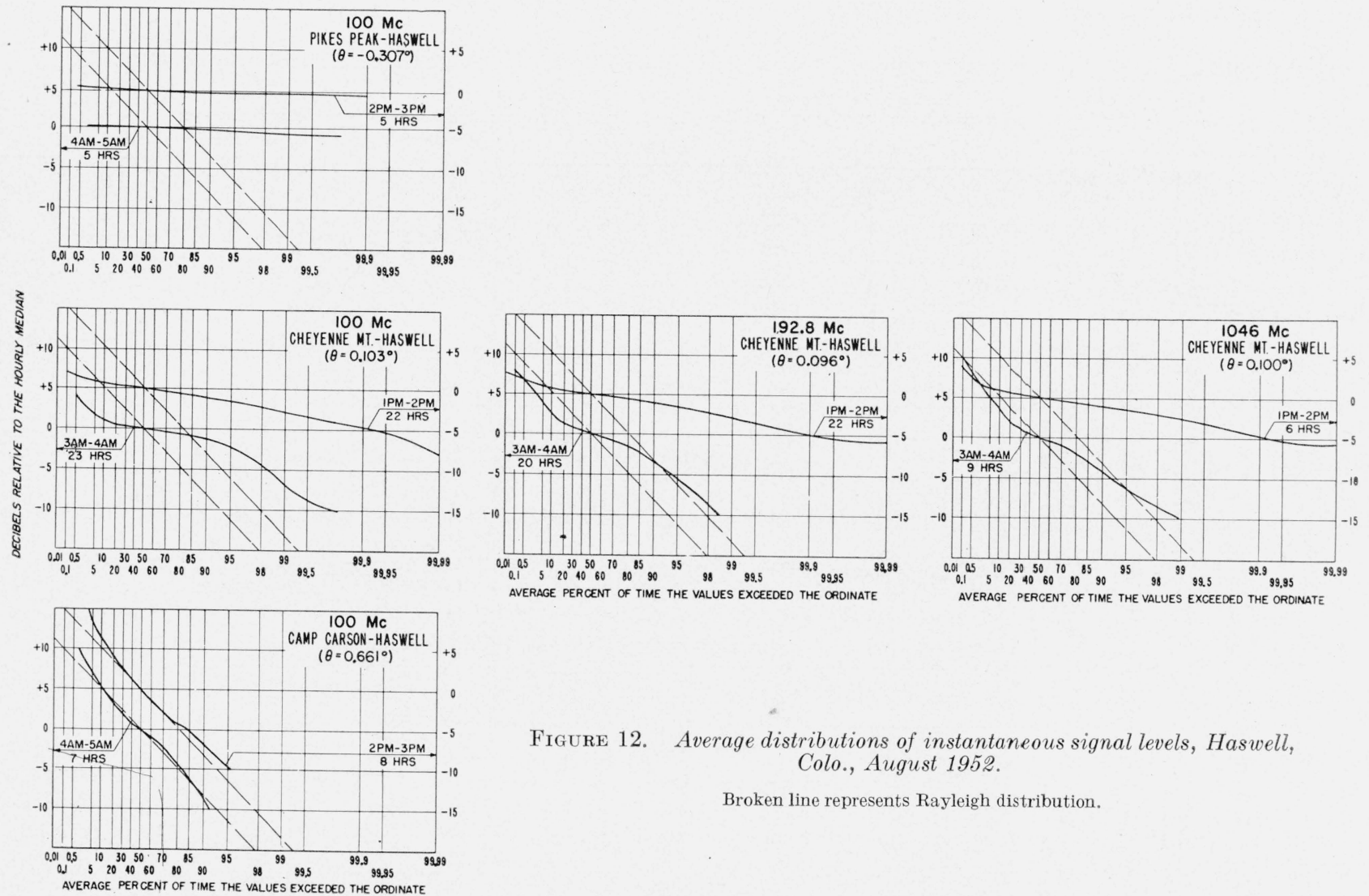

Figure 12. Average distributions of instantaneous signal levels, Haswell, Colo., August 1952.

Broken line represents Rayleigh distribution. 

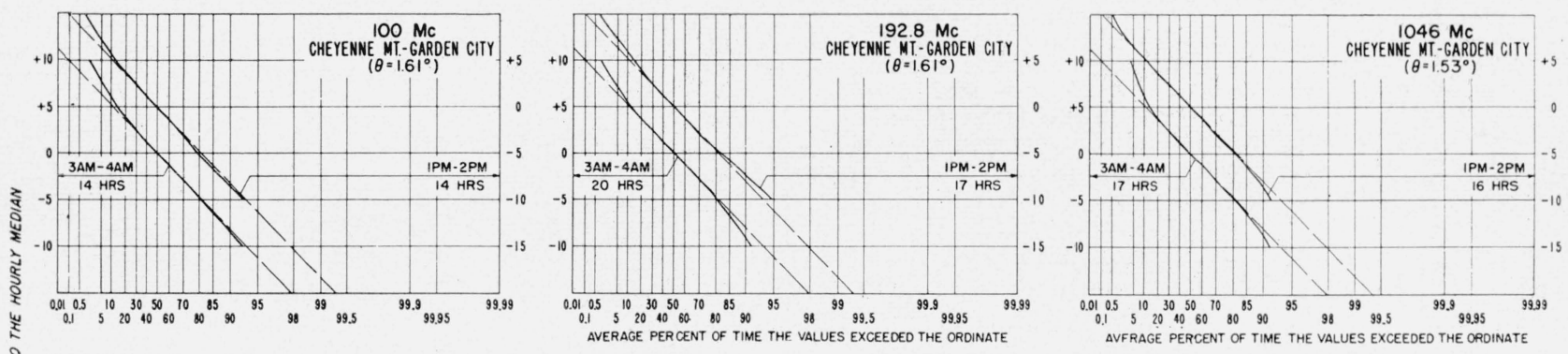

Figure 13. Average distributions of instantaneous signal levels, Garden City, Kan., August 1952.

Broken line represents Rayleigh distribution,

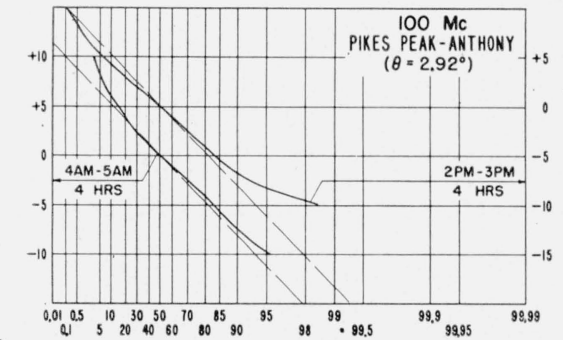

है
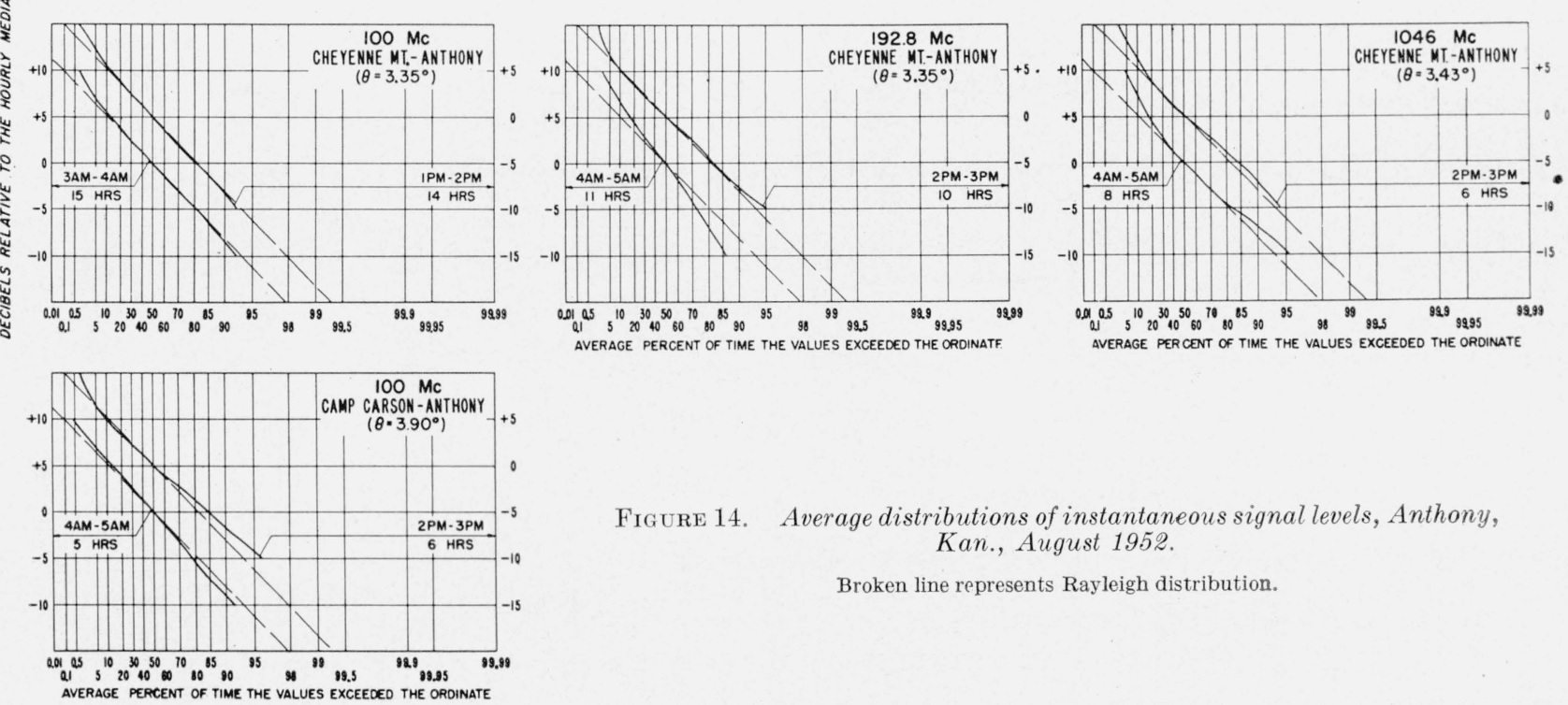

Figure 14. Average distributions of instantaneous signal levels, Anthony, Kan., August 1952.

Broken line represents Rayleigh distribution. 


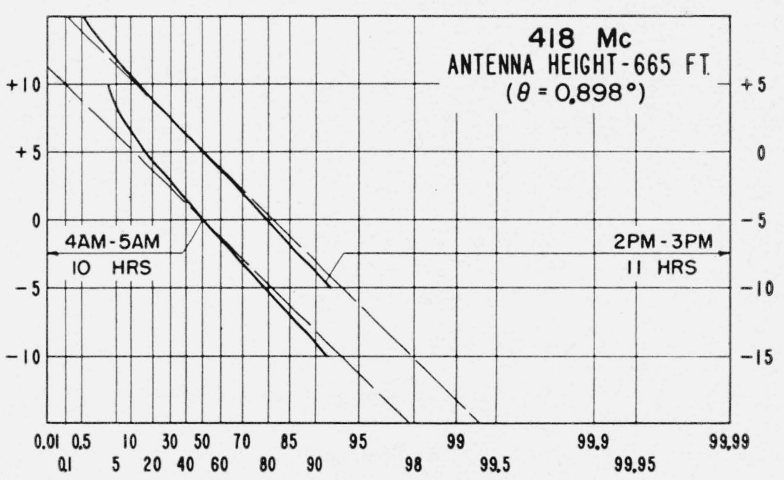

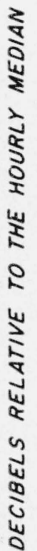
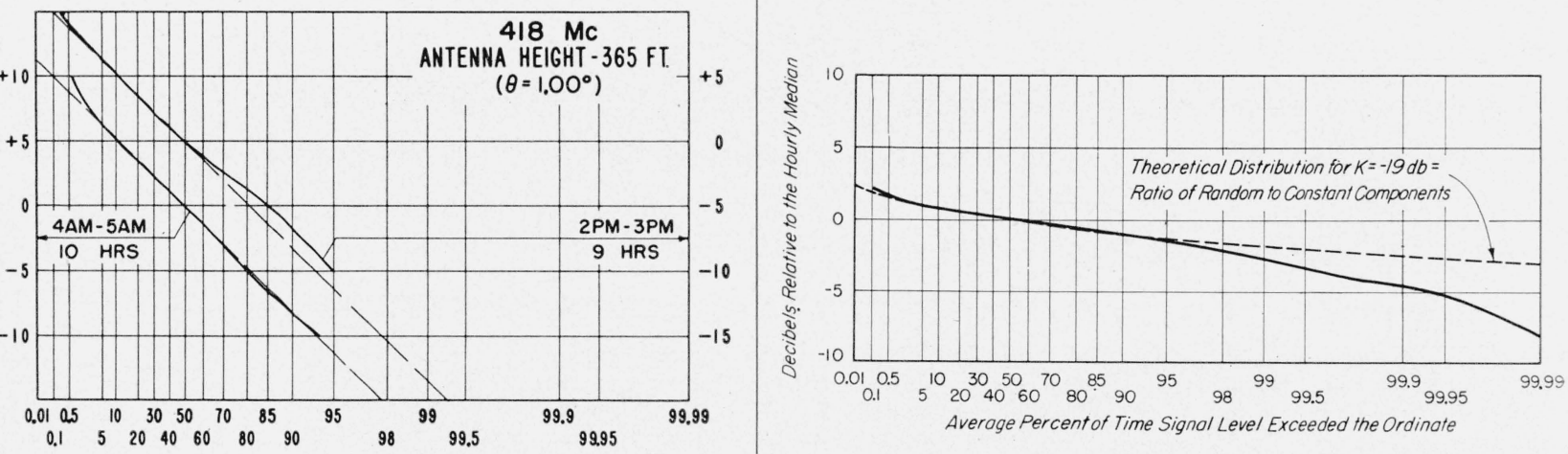

Figure 16. Average distribution of instantaneous signal levels, Cheyenne Mountain-Haswell path, August 1952, $100 \mathrm{Mc}$.

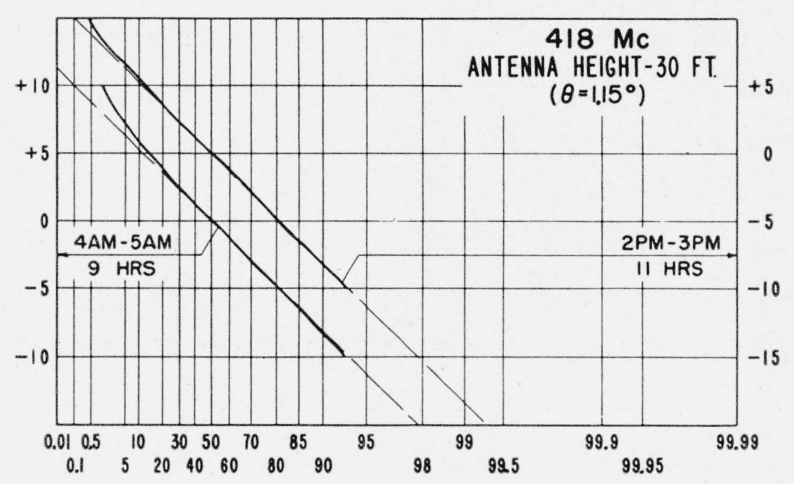

AVERAGE PERCENT OF TIME THE VALUES EXCEEDED THE ORDINATE

Figure 15. Average distributions of instantaneous signal levels, Cedar Rapids, Iowa to Quincy, Ill., August 1952. Broken line represents Rayleigh distribution.]

$$
\theta=0.103^{\circ}, 1 \text { to } 2 \mathrm{p} . \mathrm{m},, 22 \mathrm{hr} \text {. }
$$




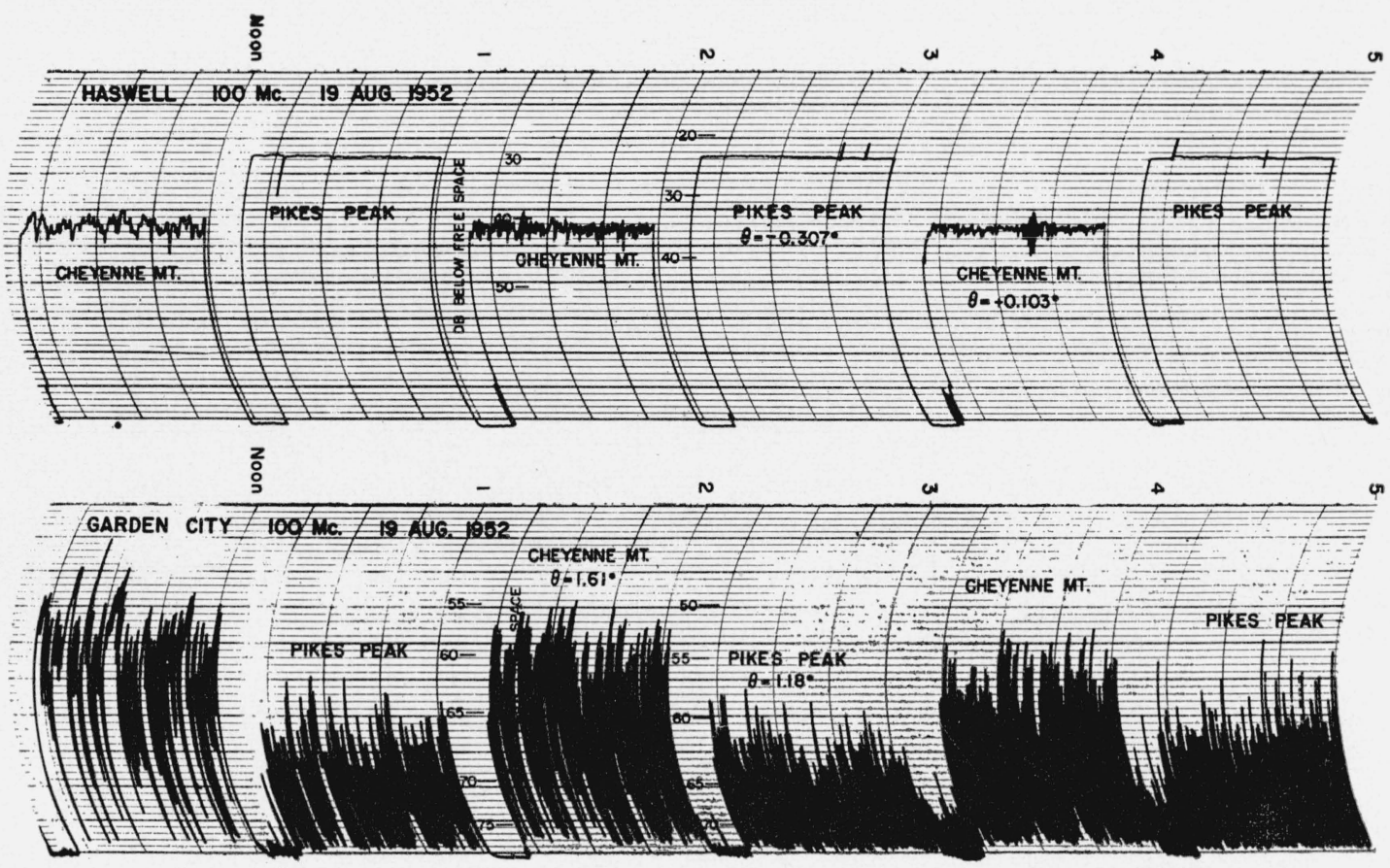

FIGURE 17. Comparison of fading characteristics in relation to angular distance below the radio horizon.
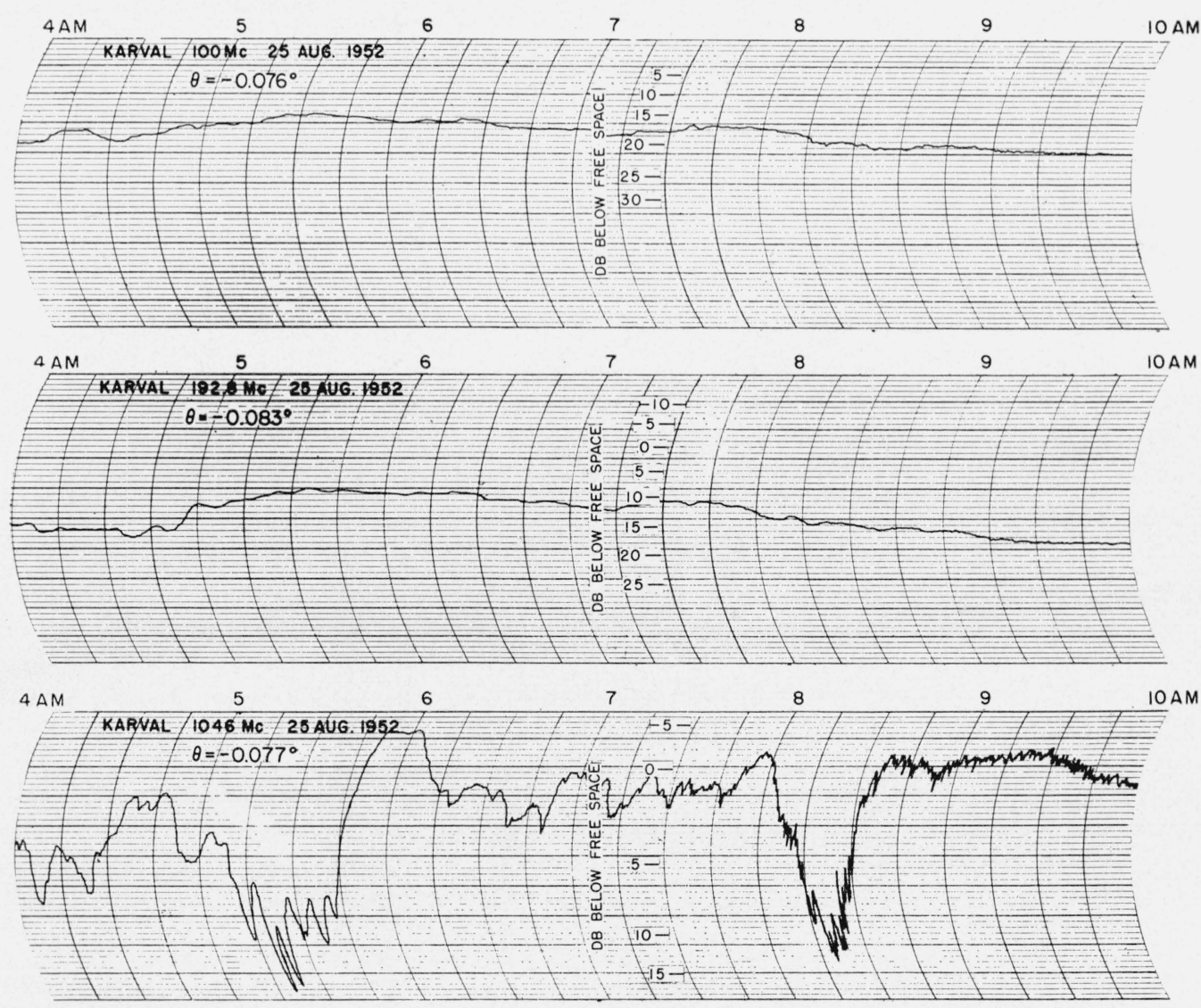

Figure 18. Sample fading characteristics of three radio frequencies, Cheyenne Mountain-Karval path. 

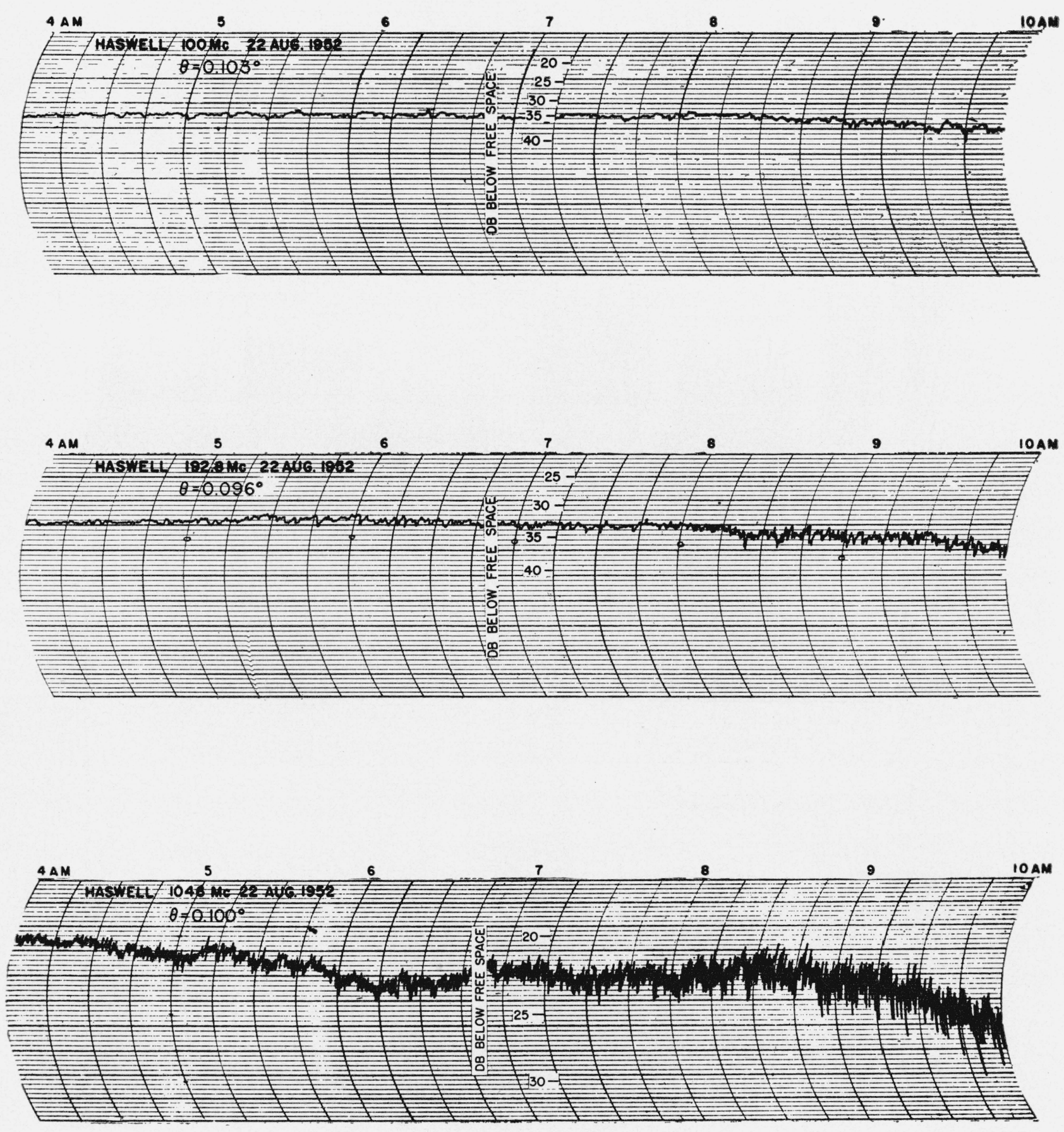

Figure 19. Sample fading characteristics for three radio frequencies, Cheyenne Mountain-Haswell path. 

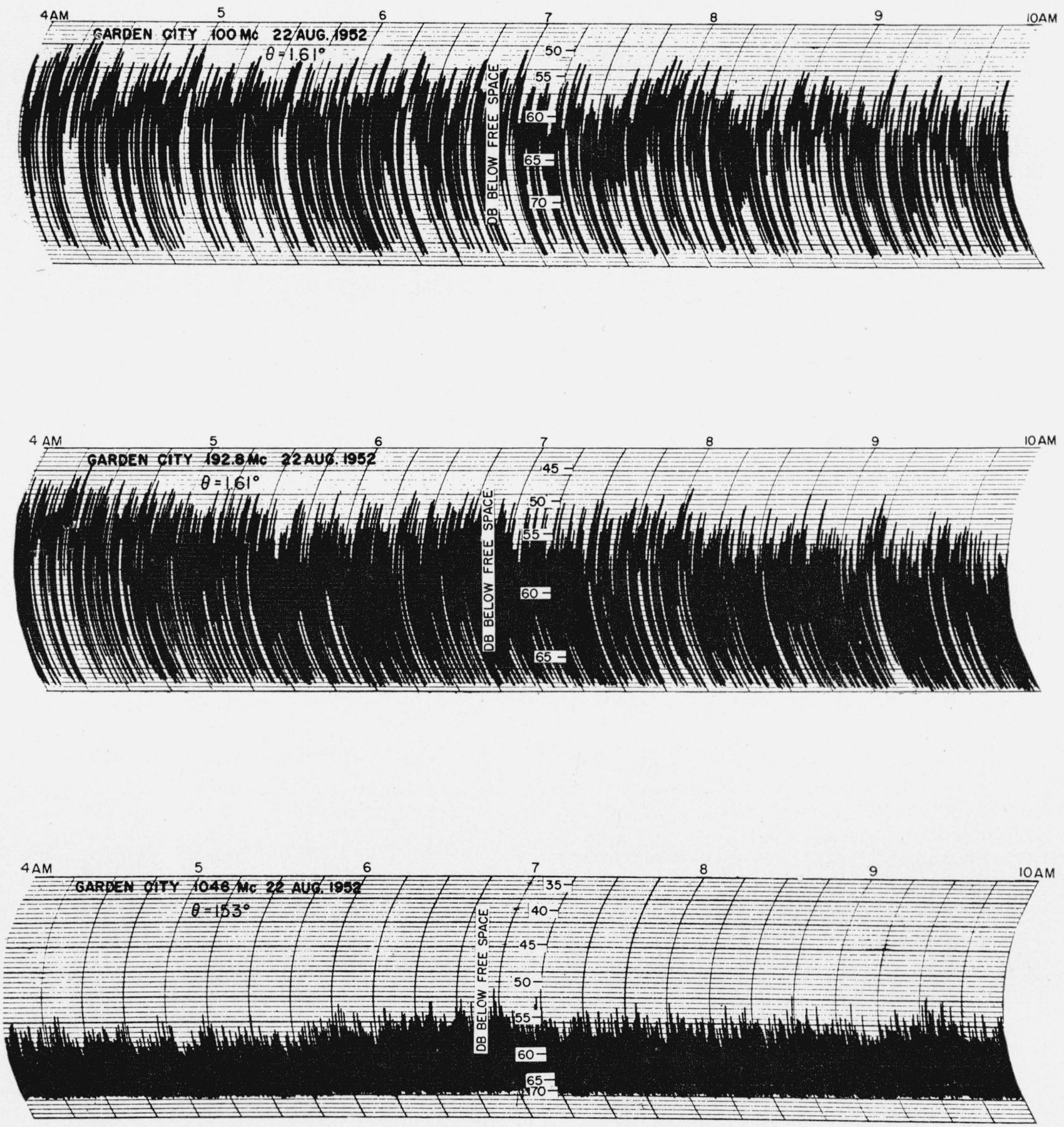

Figure 20. Sample fading characteristics for three radio frequencies, Cheyenne Mountain-Garden City path. 

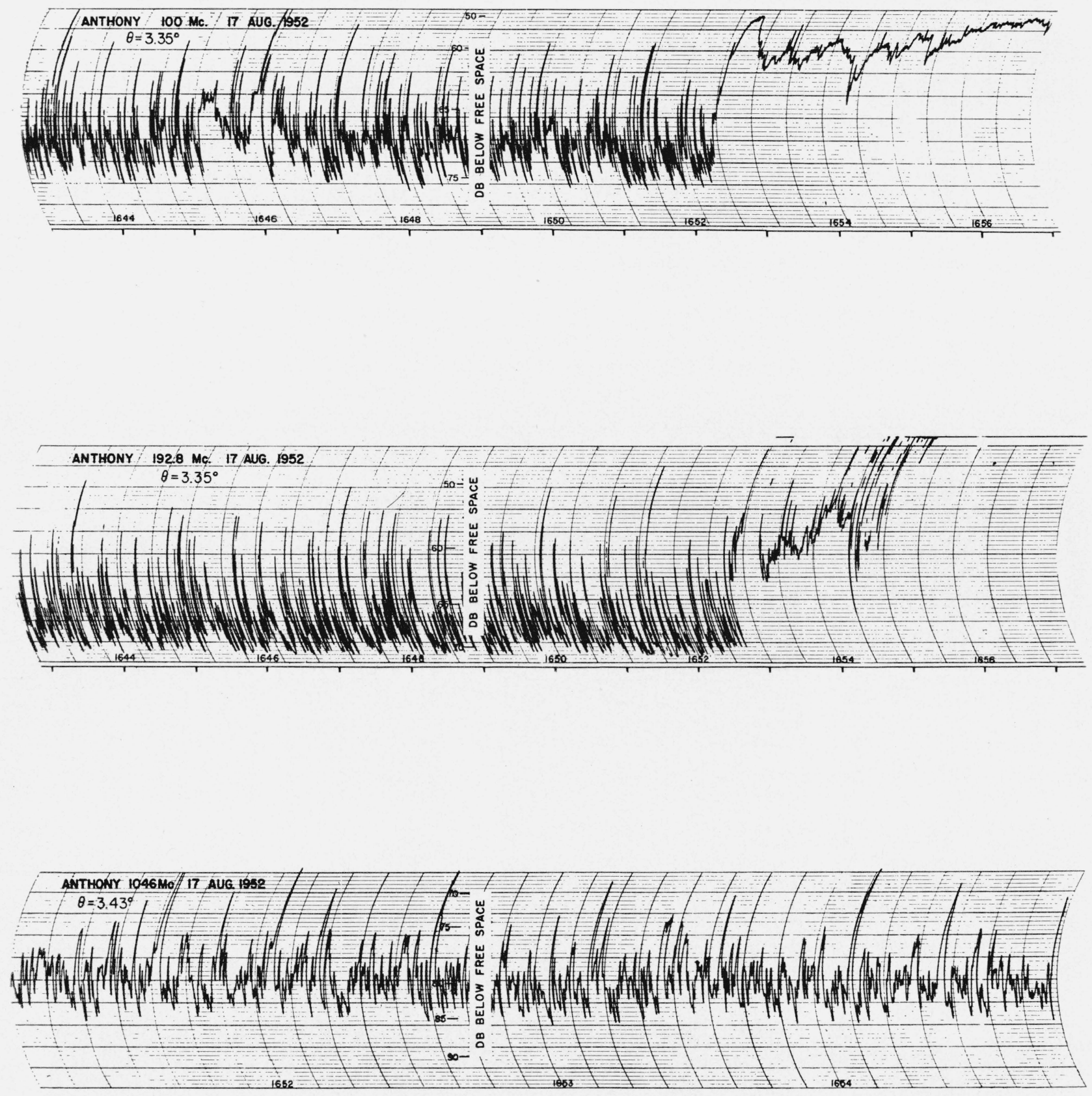

Figure 21. Sample fading characteristics for three radio frequencies, Cheyenne Mountain-Anthony path. 

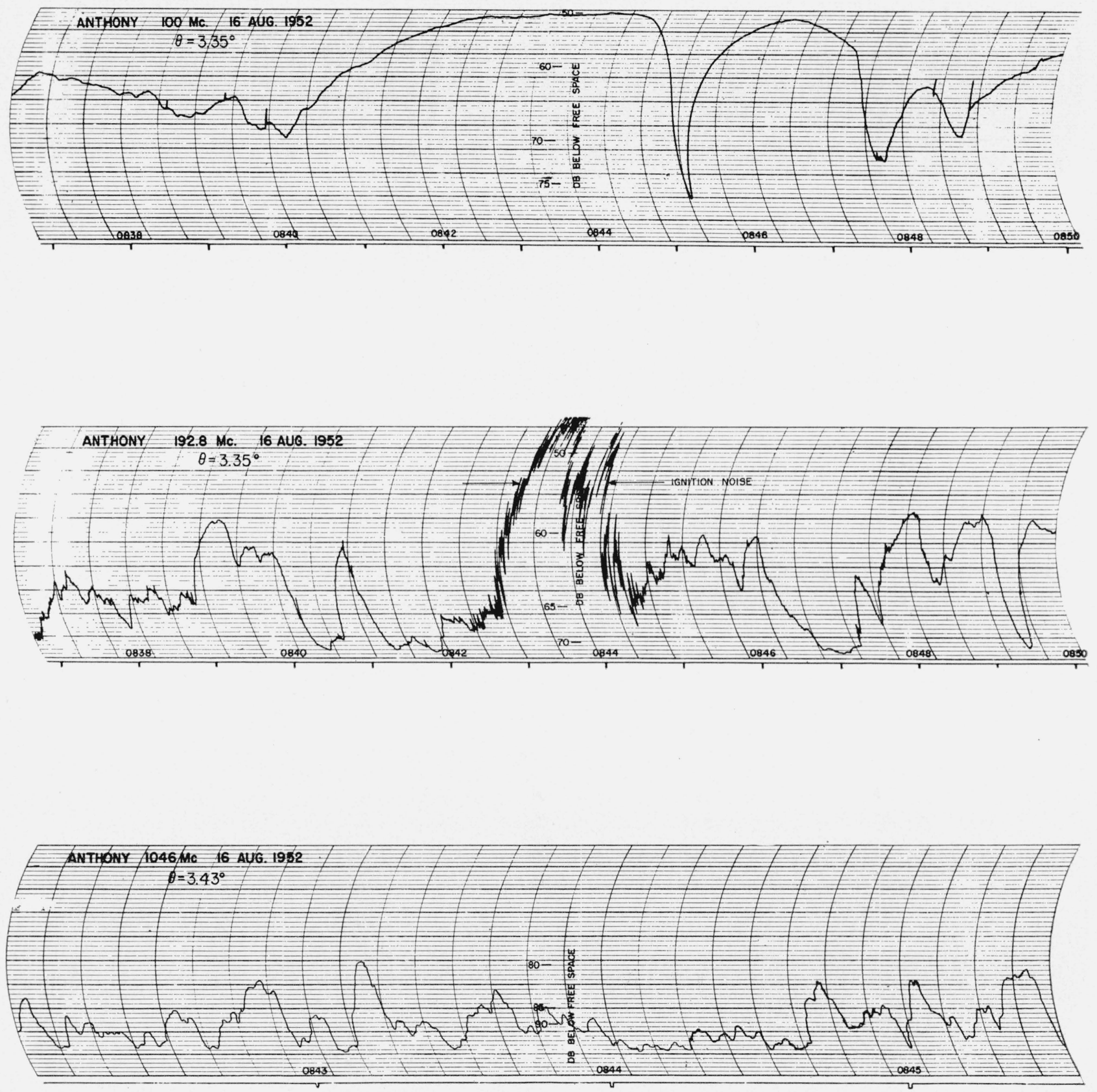

Figure 22. Sample fading characteristics for three radio frequencies, Cheyenne Mountain-Anthony path. 

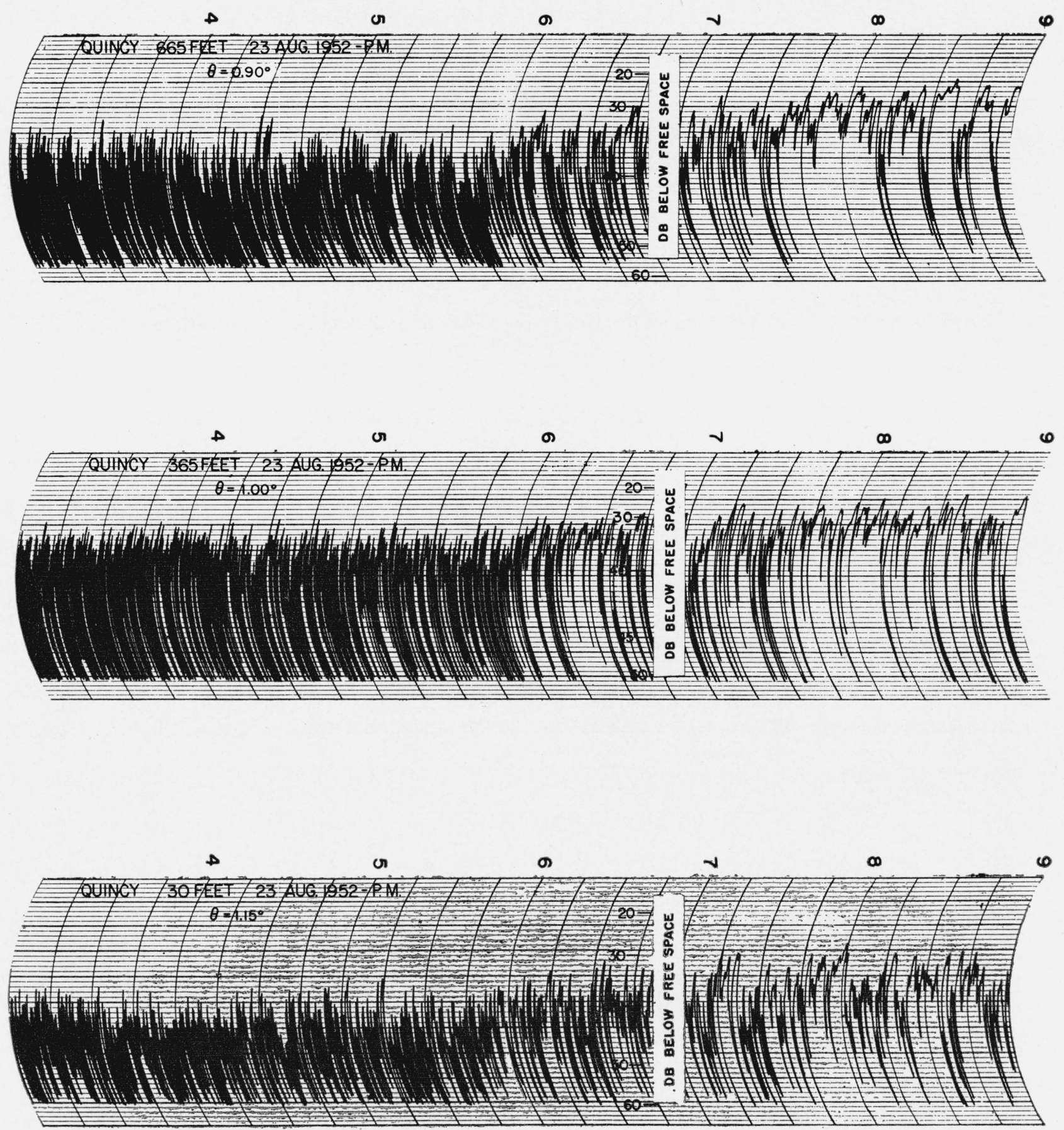

Figure 23. Sample fading characteristics at 418 Mc for three receiving antenna heights, Cedar Rapids-Quincy path.

Boulder, Colo., December 1, 1954. 